believe, belongs. I know from what we found at the operation that the infection was widespread, but $I$ think that it is doubtful if it involved the upper part of the peritoneal cavity. The recovery of the patient is, I think, evidence that it probably did not do so. When the great disappointment which is often experienced after trying to save a case of widespread infection of the peritoneal cavity, from perforation or gangrene of the appendix, by operation, is borne in mind, it seems to me worth while recording successful cases, as an encouragement to operate if the opportunity presents itself early enough. This case appears to me to teach a lesson well worth learning, and that is that operation in recurrent cases cannot always safely be postponed until the quiescent period. We cannot feel assured that because a patient has had several attacks of appendicitis the appendix must therefore be safely buried in adhesions and the risk of infection of the surrounding peritoneum almost nil. My case is an instance of a most serious infection of the peritoneal cavity in the fourth attack of appendicitis, and I have collected a considerable number of cases of such serious infection in recarrent attacks. The case is also of interest as an illustration of the fact that serious infection of the peritoneum may be present and yet the general condition of the patient be remarkably good: These are just the cases in which an early operation is attended with the best results, for the patient is saved from the gravest possible danger and the operation is performed at a time when his strength is well equal to it.

The patient was a man, aged 44 years. He woke up on the morning of Dec. 4th, 1900, with some slight abdominal discomfort, and during a journey of several hours to Bristol in the morning the pain became severe. It was present in the right iliac fossa, but also darted up and down the right side of the abdomen in the line of the right rectus muscle. He did not vomit. He was seen by Dr. Barrett Roue in the afternoon and I saw him with Dr. Roue in the evening. His pain had then been a little relieved by opium. His pulse was only 80 and the temperature was under $100^{\circ} \mathrm{F}$. The abdomen was very little if at all distended, but the right side was rigid. It was only tender over a small area just inside the right anterior snperior spine. There was a normal amount of abdominal breathing. No swelling was present. There was a history of three previous attacks, one in July, another in Angust, and a third in October. The diagnosis of appendicitis seemed clear and as there had been three previous attacks I thought we might safely watch the case. On the following day (the $5 \mathrm{th}$ ) the patient complained of pain in a very unusual position - the left side of the perineum and in the penis, and he said that it started in the right hypochondriac region and spread down the line of the right rectus muscle into these parts. The abdomen was somewhat distended and also slightly rigid and tender on the left side as well as on the right. He had no vomiting, although he was taking a fair amount of milk. Only one-sixth of a grain of morphia had been given hypodermically on the previous evening. On the next morning (the 6th)-that is, 48 hours from the commencement of the attack-there were more abdominal distension and more general tenderness and the abdominal breathing had disappeared. Although the pulse was only 80 and the temperature was below $100^{\circ}$ and the patient showed no sign of prostration I decided to operate as the increasing general distension and tenderness seemed to be unsatisfactory signs. Not that general distension alone is a certain sign of widespread peritoneal infection in these cases, for in some of my cases of appendicitis in which it has been marked the disease was strictly limited to the appendix.

I opened the abdomen over the region of the appendix and found what $I$ have observed in other cases of intraperitoneal suppuration, very marked cedema of the connective tissue just beneath the external oblique aponeurosis. On dividing the peritoneum a very red and distended cæcum presented and from beneath this I evacuated a small collection of pus which was only retained there by the pressure of surrounding distended coils of intestine. I next passed a sponge on a holder down into the true pelvis, and on withdrawing it a large quantity of thick pus escaped from the pelvis, which was then thorougbly sponged out. All the coils of intestine which presented in the wound were very red and had exudation of lymph on them. The appendix was perforated close to its attachment to the cæcum, and I removed it. It was almost free from adhesions. A very long glass drainagetube was placed in the pelvis, another in the right loin, and a small one against the stump of the appendix, and gauze wicks were placed in the tubes. There was no shock from the operation, but I must say that the condition of the peritoneum was so bad that I did not expect the patient to recover. In spite of my fears, however, he began to improve from the time of the operation; flatus was passed and the abdominal distension slowly subsided. He was fed only by the bowel for the first 48 hours, and occasionally turpentine enemata were given. Only serum drained away from the tubes, but this came in considerable quantity at first, though the quantity soon diminished, and a few days after the operation the glass tubes were changed for rubber ones. He never had very much pain after the operation and had no vomiting at any time during his illness. Ten days after the operation the abdomen was sof $t$ and of natural shape and he was taking fish and other kinds of solid food. All the rubber tubes were removed five days after the operation, but on the following day for the first time a little pus was discharged from the drainage-tube track leading to the stump of the appendix. As the discharge continued a very small drainagetube was inserted into the track and a slight discharge persisted for a fortnight and then the sinus healed. The patient made a satisfactory convalescence and has since remained quite well.

1 think the record of this case will show how dangerous a recurrent case of appendicitis may be, and that severe peritoneal infection may be present with a pulse bardly raised above normal, a very slight rise of temperature, and a complete absence of vomiting and of those signs of general prostration which are so frequently associated with septic peritonitis. I hope that by adding one more to the list of recorded successful cases of operation I may give some further encouragement to operate for septic peritonitis if the patient is seen early enough.

Bristol.

\section{THE OPEN-AIR TREATMENT OF PHTHISIS} AT HOME :

A SHORT HISTORY OF A CASE.

BY F. WHINFIELD BARTLETT, M.R.C.S. ENG., L.R.C.P. LOND.

THE patient, aged 38 years, the wife of a baker residing on his business premises in the country, two miles from a small town, had, before coming under my care, been treated by my predecessor for phthisis. During the years 1897, 1898 , and 1899, she consulted me on several occasions for attacks of pleurisy on the left side. During the winter months she suffered much from congh and shortness of breath. There were well-marked physical signs of consolidation in the upper lobe of the left lung, with a cavity at the apex. In the intervals between the pleuritic attacks she felt well enough to perform her ordinary household duties and continued to do so until the onset of more acute symptoms in January, 1900. There was no history of tuberculous disease on her father's or her mother's side, bnt her only child, a boy, aged nine years, had suffered from taberculons disease of the knee-joint, for which I bad amputated through the thigh in September, 1899. He has never developed any pulmonary symptoms.

On Jan. 8th, 1900, I was called to the patient's house and found her in bed. She had been shivering, the pulse and respiration were both very rapid, the temperature was $102^{\circ} \mathrm{F}$., and there were much cough and expectoration. These symptoms continued to be very acute for a fortnight. then they gradually remitted until in the first week in February her condition was as follows. The body was considerably wasted (her weight was $89 \mathrm{lb}$.), her evening temperature averaged $100 \cdot 6^{\circ}$; there was considerable dyspnœea; respinations were from 30 to 40 per minute; there were severe night-sweats and much congh with expectoration of large quantities of viscid mucus (this had declined from four or five ounces to about two ounces per diem), sometimes muco-purulent and always containing "nummuli" and sometimes streaked with blood. There was much bodily weakness with anorexia and great restlessness and nervous irritability. With regard to physical signs there were marked flattening and deficiency of respiratory movement on the left side; the left clavicular note was quite dull; the percussion note was quite dull at the apex and was markedly impaired 
over the whole of the remainder of the left lung, front and back; the breath-sounds were cavernous at the left apex with very distinct bronchophony and pectoriloquy and much coarse metallic rale. The breathing became bronchial in the axillary region and faded to a weak respiratory murmur over the base, where also pleuritic friction sounds were to be heard. There were also signs of commencing disease of the right apex. A specimen of the sputum was sent to the olinical Research Association for examination, and the report was that " tubercle bacilli are present in small numbers."

As the prospect of the patient's recovery seemed to be under ordinary conditions very slight $I$ advised that she should undergo the open-air treatment. To this she and her friends willingly consented, but as residence in a sanatorium was out of the question, I persuaded them, being influenced by the account of a very successful case reported by $\mathrm{Mr}$. T. A. Somerville and Dr. Eugene S. Yonge,${ }^{1}$ to carry out the treatment at home. For this purpose a shepherd's van which happened to be on the premises was moved into the garden at the rear of the house. The side of the van facing south was removed and rebuilt to the height of three feet six inches from the floor, leaving a space of four feet between it and the roof the whole length of the van, provided with shutters for use in stormy weather. A small stove with a flue was placed in the van for the sake of comfort, and the patient then took up her residence there. The season was winter (she commenced the treatment on Feb. 7th) but she spent the whole of the time between breakfast and sunset lying on a couch or sometimes sitting in an easy-chair in this situation with the exception of half an hour for dinner in the middle of the day, when she went in-doors. Whilst in-doors-in her sitting-room in the evening and in her bedroom at night-the window was always kept wide open, a screen being placed between the window and the bed to prevent any draught being felt. Although the other occupants of the house complained of the cold and discomfort she herself felt no inconvenience even in the coldest weather. Occasionally, in very stormy weather she would remain in-doors for a day or two, wind and a damp atmosphere apparently causing laryngeal catarrh, whilst a cold dry air had no such effect. When the weather was favourable she took short walks. She was enjoined to take a liberal diet, but her distaste for food was such that she could never take much meat or solid food of any sort. Her usual daily menu was three pints of milk, one egg, a little bacon (at breakfast), a few thin slices of bread-and-butter, occasionally a little meat and vegetable, and, in the winter months, a plate of oatmeal porridge with milk for supper. During the first three or four months of treatment she took a capsule containing one minim of creasote three times a day. She also used inhalations of terebene several times daily, and frequently took an anodyne cough mixture. I visited the patient twice a week during the first few months of treatment, and afterwards at gradually lengthening intervals. She kept a daily record of her morning and evening temperature and a weekly record of her weight. Within a week or two of her taking up her out-of-door residence her condition began to improve-the cough diminished in frequency and the sputum in amount, the evening temperature fell to below $100^{\circ}$, and she commenced to gain in weight. In the first seven weeks she gained $7 \mathrm{lb}$,; then her weight remained practically stationary for two months. During this period the evening temperature averaged about one degree above normal. In April she had a slight relapse; the temperature rose to $101^{\circ}$ (for a few days it was $102^{\circ}$ ), there were considerable prostration and nervous irritability, and she was much troubled with laryngeal hoarseness and cough, so that I deemed it advisable that she should remain indoors and in bed. Under the influence of rest and warm inhalations of compound tincture of benzoin the symptoms subsided and in a week or two she was able to resume her outof-door life. After this, with the exception of a second slight relapse in May, the improvement was gradual but continuous.

The record shows that the fall in temperature and the gain in body-weight proceeded pari passu. By the beginning of August the evening temperature had fallen to normal and has never once since risen above it. Her weight at that time had risen to $102 \mathrm{lb}$; by the end of the year it had increased to $114 \mathrm{lb}$., at which it remained at the beginning of February, 1901. The improvement in her condition at

The Lancet, Jan. 20th, 1900, p. 162 this time, 12 months after the commencement of the treatment, is very marked. In place of being a fragile, cachectio worman with sunken cheeks and a hectic flush she is now plump and well-conditioned, with a healthy complexion; in fact she complains of being uncomfortably stout. Cough and expectoration have almost disappeared-she coughs a few times in the course of the day and occasionally expectorates a little mucus which is never blood-stained. She has bad no night-sweats for many months, no hoarseness, and no pleuritic pain. As to the physical signs, there are flattening and deficiency of expansion of the chest-wall on the left side, the percussion note is dull at the apez and impaired at the base, whilst there are still tubular breathing, bronchophony, and pectoriloquy at the apex, and the breath-sounds are weak at the base. The loud metallic râle which was so audible at the apex has disappeared and there is now only a faint crepitus at the extreme end of inspiration, whilst the crepitation at the base is much less in amount and pleuritic friction is absent. The signs of commencing disease of the right apex have disappeared. There is still considerable dyspncea on exertion, but otherwise she feels quite well The Clinical Research Association reported of a specimen of sputum examined on Dec. 24th, 1900, "No tubercle bacilli were discovered."

It remains to be added that beyond the fact of its being situated in the country the patient's residence presented no special advantages for the carrying out of the treatment. It is situated in the low-lying valley of a river where mist and fog are very prevalent. On the other hand, the patient and her friends are people of intelligence; they entered into the treatment with zest and carried it out with zeal and thoroughness, and to this, no doubt, the satisfactory result is largely attributable.

Romsey, Hants.

\section{Clinital a}

MEDICAL, SURGICAL, OBSTETRICAL, AND THERAPEUTICAL.

\section{A CASE OF CONCURRENT ERYTHEMA MULTIFORME AND ERYTHEMA NODOSUM.}

By Edward MaCulloch, M.B., Ch.B. Edin.

ALTHOUGH modern dermatological literature favours the view that erythema nodosum is but one of the many manifestations of erythema exudativum multiforme, sufficient difference of opinion perhaps remains to warrant the consideration of those rare cases where definite erythema nodosum co-exists in the same individual with other undoubted manifestations of erythema multiforme. In the following case the character of the lesions was unquestionable, and the family history has also an interesting bearing on the etiology of the disease.

The patient was a boy, 15 years of age, who came to me on Dec. 31st, 1900, complaining of "lumps on his legs and spots on his face." He had been exposed to rain and had got a wetting a few days previously. Examination of the shins revealed a typical eruption of erythema nodosum, about five nodes being visible on either shin. Each node was of about the size of a small walnut. Their colour was a dusky red and they were tender on pressure. Their margins were ill-defined and they were unassociated with itching or pain. On the middle of the extensor aspect of the left thigh there was one similar node. On the face there were a few small groups of reddish papules; some coalesced to form small raised patches, situated on the infra-orbital regions and just external to both outer canthi. A few papules were also visible on the ala nasi and adjacent parts of the cheeks. The patient's temperature was $100.5^{\circ} \mathrm{F}$. Little general discomfort was felt. I sent him home with directions to go to bed, and ordered 15-grain doses of sodium salicylate every four hours. Next morning the facial eruption had increased in extent, and fresh patches had appeared behind both ears and on the bridge of the nose. Coalescence of some of the original papules had taken place. The papules were moderately 